\title{
Climate Change: Major Initiatives and Opportunities in Nepal
}

\author{
Batu K. Uprety ${ }^{1}$
}

\section{Introduction}

Climate has changed and will continue to change through natural process. Nature and human beings will continue to adapt naturally with such changes in the climate system. Anthropogenic activities have increased the emission of greenhouse gases (GHGs) in the atmosphere. The GHGs trap the heat and raise air temperatures near the ground, acting like a greenhouse on the surface of the planet. Rise in temperature has greatly impacted the planet Earth - the life support system. The first World Climate Conference in 1979 identified climate change as the urgent global problem and called upon the international community for immediate actions. This prompted several scientific studies and conferences. The United Nations General Assembly (UNGA) recognised that "climate change is a common concern of mankind since climate is an essential condition which sustains life on earth". The UNGA decided that timely action to deal with climate change within a global framework was necessary. The World Meteorological Organisation (WMO) and United Nations Environment Programme (UNEP) established the Inter-governmental Panel on Climate Change (IPCC) and IPCC was mandated to assess the magnitude and timing of changes, estimate the impacts, and present response strategies.

The IPCC published the first assessment report in 1990 on the state of global climate. Also realising it, UNGA established the Intergovernmental Negotiating Committee (INC) on 21 December 1990 to develop a legal instrument on climate change. The INC met five times in 1991 and 1992, and adopted the text of the UN Framework Convention on Climate Change (UNFCCC) on 9 May 1992 at the UN Headquarters, New York. The Convention was opened for signature on 5 June 1992 during the Earth Summit at Rio de Janeiro, Brazil. It means Convention adoption and signature are two different aspects.

The Convention has the objective of achieving stabilisation of the GHGs concentration in the atmosphere at a level that would prevent dangerous anthropogenic interference with the climate system thereby helping to allow ecosystems to adapt naturally, not threatening the food production, and enabling sustainable economic development. The Convention calls upon the Parties to, inter alia, protect the climate system for the benefit of present and future generations with common but differentiated responsibilities and respective capabilities.

As the Convention was of framework nature, the Parties to the Convention at its third session of the Conference of the Parties (COP3) adopted the Kyoto Protocol on 11

${ }^{1}$ Ministry of Environment, Kathmandu, Nepal, Email: upretybk@gmail.com 
December 1997 in Kyoto, Japan. Article 3.1 of the Protocol obliges the Annex 1 Parties (developed/industrialised countries) to the Convention to individually or jointly ensure their aggregate anthropogenic carbon dioxide equivalent $\left(\mathrm{CO}_{2}\right.$-eq) emissions of GHGs not to exceed their assigned amounts which is included in the Annex B (Quantified Emission Limitation or Reduction Commitment, QELRC) of the Kyoto Protocol. Annex 1 Parties shall reduce the overall emission of GHGs by at least 5 percent below 1990 levels in the commitment period 2008 to 2012 . Article 3.9 of the Protocol provides provision for commitments for the subsequent periods. The Protocol also provides provisions for emission trading, joint implementation, and clean development mechanism (CDM) for carbon trading that might help the developed country Parties to meet their commitments under the Kyoto Protocol. The CDM provides the developing countries an opportunity to benefit from projects or activities that contribute to achieve the goals of sustainable development.

The Convention and the Kyoto Protocol entered into force on 21 March 1994 and 16 February 2005 respectively. The Parties to the Convention and Kyoto Protocol have met 14 and 4 times respectively by December 2008 to review implementation status and make necessary decisions for their effective implementation. The $15^{\text {th }}$ session of the COP to the Convention and $5^{\text {th }}$ session of the COP serving as the Meeting of the Parties (COP/MOP or CMP) to the Kyoto Protocol will be convened in Copenhagen in December 2009. The International community is actively working to make the Copenhagen conference a milestone for the effective implementation of the UNFCCC and KP as it might decide on subsequent commitment periods with QELRC and elements of the Bali Action Plan (BAP).

\section{Issues for COP15 and CMP5}

The COP15 and CMP5 will basically focus on BAP adopted by the $13^{\text {th }}$ session of the COP to the UNFCCC in Bali, Indonesia. The COP13 decided to adopt a decision at its $15^{\text {th }}$ session to address, inter alia:

1. A shared vision for long-term cooperative action including long-term goal for emission reduction;

2. Enhanced national/international actions on mitigation of climate change, including consideration of measurable, reportable and verifiable (MRV) nationally appropriate mitigation commitments or actions by all developed country Parties, nationally appropriate mitigation actions (NAMAs) by developing country Parties, and policy approaches and positive incentives on issues relating to reducing emissions from deforestation and forest degradation in developing counties (REDD), and role of conservation, sustainable management of forests and enhancement of forest carbon stock in developing countries;

3. Enhanced action on adaptation including vulnerability assessment, prioritisation of actions, financial needs assessments, capacity building and response strategies etc. 
4. Enhanced action on technology development and transfer by, inter alia, removing obstacles; and

5. Enhanced action on the provision of financial resources and investment to support action on mitigation, adaptation and technology cooperation.

In addition, CMP to the Kyoto Protocol at its $5^{\text {th }}$ session is expected to decide on QELRC for the next commitment period for which negotiation process was started in 2005 . There are several outstanding issues for COP15 and CMP5. Several ideas, concerns and issues have been raised in the previous meetings of the climate change regime, popularly known as the climate change talks, to promote discussion and negotiation for concrete decisions on BAP elements in December 2009. Negotiation is a Party-driven, open, transparent and inclusive process and each Party could participate in negotiations. Some of the floating issues under negotiation are listed below:

1. Long-term goal should be ambitious or inspirational or indicative. Emphasis has been given to fully respect the "right to survival" and "right to development", and provide technologies and additional finances to the developing countries in the spirit of the Convention.

2. Parties, in principle, agree to address sufficiently the impacts of climate change which should be guided by science and pragmatism. It should consider the principle of responsibilities, in particular the historical responsibilities for GHG emissions, "polluter pays principle", and common but differentiated responsibilities and respective capabilities. It is equally important to promote low emission economic development.

3. The KP has included 5.2\% GHG reduction by 2012 (first commitment period, 20082012) at 1990 baseline. There are several proposals on emission reduction such as at least $45 \%$ by 2020 at 1990 base year, $15 \%$ at 2000 reference year; $20 \%$ at 2006 level; $20-30 \%$ at 1990 level, and 15\% at 2005 level etc. Hence, outstanding issues on second commitment period are base year, emission reduction commitment, commitment period (2013-17 or 2013-2020), medium-term commitment (by 2020) or long-term commitment (by 2050) etc. As of 28 July 2009, nothing has been agreed upon and it is expected for agreement in December 2009 in Copenhagen.

4. Issues related to adaptation, mitigation, technology development and transfer, and financing including capacity building are also to be negotiated in COP15 and CMP5. In order to operationalize the decisions, institutional and financial architecture including provisions for technology transfer, easy and direct access to financial resources are extremely important. 


\section{Climate change in Nepal}

Nepal participated in the climate change business right from the Convention preparation process in 1991. Nepal signed the Convention on 12 June 1992 during the UN Conference on Environment and Development at Rio de Janeiro, Brazil. The instrument of ratification was submitted to the Convention Depository on 2 May 1994 and the UNFCCC has entered into force in Nepal on 31 July 1994 (90 days after the submission of the instrument of ratification) as per the Convention provision. Similarly, Nepal submitted the instrument of accession to the Kyoto Protocol to its depository on 16 September 2005. The Protocol has entered into

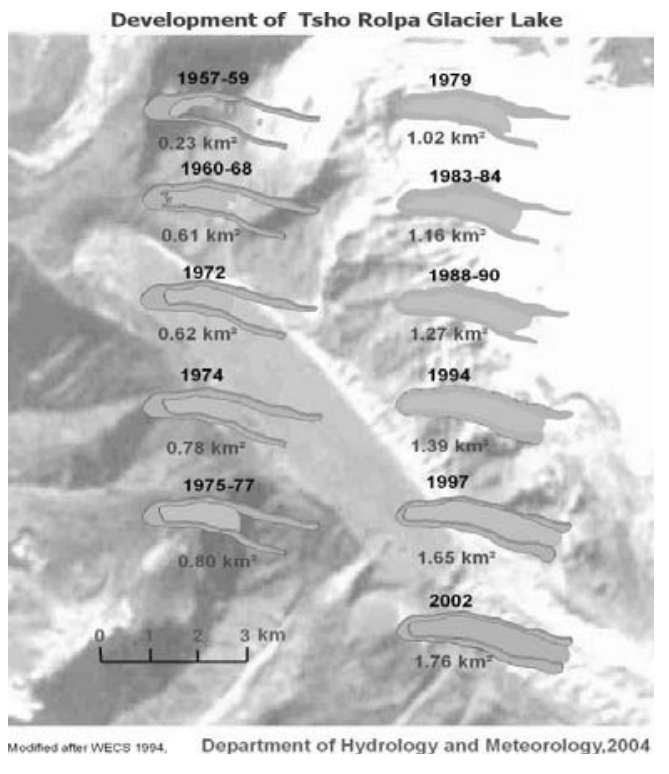
force in Nepal on 14 December 2005. In order to expedite CDM projects, and get benefits from them, the Government of Nepal has made the Ministry of Environment $(\mathrm{MoE})$ responsible to function as the Designated National Authority (DNA) on 22 December 2005.

Nepal is very much susceptible to climate change. Although Nepal shares less than 0.025 percent of the global GHGs emission, it is already witnessing the visible effects of climate change such as accelerated snow and glacial melting thereby increasing in the size of glacial lakes that might increase GLOF (Glacier Lake Outburst Floods). The Tso Rolpa lake is an excellent example of increasing size in the Nepal Himalaya. Climate change induced impacts are also noticed in rainfall variation, and forests and biodiversity. Landslides, floods and unexpected droughts are increasing which might have a direct bearing on human health and food security. The number of cold days and cold nights are decreasing or number of hot days and hot nights are increasing. Impacts of climate change in the Himalayas would have multi-fold and unimaginable effects in the downstream thereby requiring additional efforts to lessen the impacts of climate change both at the origin and the downstream. Nepal Himalayas are the major sources of freshwater not only for Nepal but also for South Asia. Global warming has affected Himalayas resulting in retreat of glaciers of which over 20 are very vulnerable.

Predictions indicate that Nepal's rivers will enjoy increased water flow by 2030 and suffer from reduced flow by the end of $21^{\text {st }}$ century. It is considered that snow melting will increase water flow up to a certain period after which it might gradually decrease which might be attributed, inter alia, to snow formation process. In this context, it is natural to think that international community should have additional understandings on natural linkages, interrelationships and interdependencies between the mountains and the lowlands. 


\section{Major activities on climate change regime}

Although Nepal participated in the Convention process from the very beginning, recently the full implications of climate change for Nepal has been realised and Nepal has initiated activities for the implementation of the Convention. The year 1994 has been considered here as the base year as the Convention was entered into forced this year in Nepal. Some of the activities, implemented and/or under implementation by the environment ministry, listed below refer to: (i) 1994 to 2005; and (ii) 2006 onwards.

a) In between 1994 and 2005, Nepal conducted an inventory of GHGs for energy sector in 1994, conducted two separate studies on implementation strategy on environment related conventions and identified potential linkages amongst the three Rio Conventions (UNCCD, CBD and UNFCCC) in 1999 and 2000, and prepared the first initial national communication (INC) report which was shared with the Parties to UNFCCC in 2004. This INC report has been the building block to initiate climate change activities in Nepal in the spirit of the Convention. In 2005, the Government of Nepal has made the Ministry of Environment (MoE) responsible to function as the Designated National Authority (DNA) for the CDM projects in order to get benefits from such projects.

b) From 2006 onwards, following activities have been initiated:

1) The Ministry issued the CDM project approval procedures in 2007. For this, MoE has constituted the Steering Committee and Technical Advisory Committee (on caseby-case basis) for guidance and technical inputs in the CDM projects. It organises the stakeholder consultation and evaluates the CDM projects based on the approved sustainable development criteria before approval of any CDM project. The Project Idea Notes (PINs) and Project Design Documents (PDDs) of the some of the CDM projects have already been approved by the DNA to facilitate carbon trading.

2) In order to coordinate the climate change activities, the government has also constituted a 23-member Climate Change Network (CCN) under the chairmanship of the Secretary of the MoE in early 2007. The functions of the CCN are (i) to identify working areas; (ii) conduct policy/field level research and studies and implement activities based on the capacity and expertise; (iii) promote CDM related activities, and launch public awareness and capacity building programs; (iv) develop status/position papers for the Parties meeting and negotiation capacity; and (v) develop Climate Change Clearing House for easy information sharing. The CCN has been represented by representatives of the government ministries, intergovernmental organisation, international NGOs, academia, private sector, donors and multilateral organisations.

3) The Climate Change Policy has been drafted through stakeholder consultation and is in the final stage of refinement. 
4) The MoE has completed the implementation of the National Capacity SelfAssessment (NCSA) Project. An action plan for capacity building activities for the implementation of 3 Rio Conventions (UNFCCC, UNCCD and CBD) has been prepared.

5) The MoE has recently started the preparation of the National Adaptation Programme of Action (NAPA). The NAPA Project includes 3 components: (i) preparation of NAPA; (ii) development of climate change knowledge management and learning platform; and (iii) development of multi-stakeholder framework of action on climate change. An inception workshop was organised in May 2009 to collect ideas and concerns of the stakeholders on the project activities. The thematic areas, identified for the NAPA process, include: (i) agriculture and food security; (ii) climate-induced disasters, (iii) forest and biodiversity; (iv) water resources and energy, and (v) public health and urban settlements. The thematic working groups are expected to shortly initiate the work.

6) A project named strengthening capacity for climate change and the environment is also under implementation with outputs of: (i) strengthening the country capacity for environment and climate change management, (ii) establishing effective legal policy, and institutional framework for integrating environment and climate change into the national development agenda, and (iii) developing and implementing public education, information and awareness on environment and climate change. The project will likely contribute, inter alia, to mainstreaming environmental protection and climate change aspects into sub-national administration, strengthening negotiation capacity, and establishing service track/career path for the management of the environment within civil service.

7) The MoE will shortly start the implementation of a project on expedited financing of Climate Change enabling activities Part II: expedited financing for measures for capacity building in priority areas. This project will contribute to: (i) identification of technology needs; (ii) capacity building for participation in systematic observation networks; and (iii) preparation of technology-related programmes to address climate change.

8) The MoE has conducted an awareness raising workshop on strengthening the national capacity of developing countries to assess and develop policy options for addressing climate change across sectors and economic activities. Under this project, investment and financial flows on key sectors such as agriculture, water resources, and forestry are expected to be assessed.

9) The MoE has recently secured funding for the preparation of the Second National Communication. This project will conduct a GHG inventory, vulnerability assessment, 
promote observation system, and prepare and share the second national communication report with the Parties to the UNFCCC and KP.

10) Under the strengthening the national capacity on climate change regime project, the Ministry will prepare the status papers for COP15/CMP5, support for participation in COP15/CMP5; also support for Regional Conference on Climate Change; and raise public awareness.

11) In order to promote CDM activities and strengthen the DNA, MoE has received expert services. This will contribute to the review of PIN and PDD approval processes and consider SD criteria, organise training and knowledge sharing on CDM, support in developing CDM training for stakeholders in Nepal, and facilitation of multi-stakeholder consultation process.

12) The Government of Nepal has accessed the Pilot Program for Climate Resilience. Although the concept is at the evolving stage, it is expected that this pilot programme will contribute to increase capacity to integrate climate resilience into country strategies, awareness of climate change impacts, access to financing, and improve coordination.

13) Similarly, the Government of Nepal has also accessed the Japan launched Cool Earth Programme. Programmes and Projects have to be developed and submitted for securing funding from this initiative.

These activities initiated in 2006 are expected to be instrumental in paving the way for climate change activities in Nepal. Realizing the national needs and international concerns on climate change, establishment of the Climate Change Council is also in the process to provide guidance and expand climate change activities in the country.

\section{Opportunities}

As the impacts of climate change are inevitable, adaptation would be the area of prime concerns for Nepal. Being the most vulnerable mountainous countries and greatly affected by the impacts of climate change, collaborative efforts are expected to provide ample opportunities for sustainable economic development and sustained management of natural resources in Nepal. The climate change regime, if implemented in "good faith" in accordance with the provision, inter alia, Article 4.9 of the Convention, would contribute a lot in building capacity, ensuring financial flows and technology transfer, and implementing a number of adaptation activities and promoting carbon sinks, and also promoting clean energy development path or expand low emission economy in the country. Nepal is affected and will continue to be affected by the poison although it has not taken it. Hence, Nepal needs to take them as opportunities and should make every effort to benefits from the climate change regime. This might be one of the areas for financial flows for socio-economic development of the country. 